\title{
ALEJANDRO HERRERA*
}

\section{Utilitarismo y ecología*}

La problemática ambiental ha rebasado los límites de la ecología como ciencia biológica y ha adquirido definitivamente una dimensión ético-filosófica, al menos desde 1973 (Routley), y ahora, en los medios académicos, es común hablar de ética ambiental o ecológica. Aunque se discute si se trata de una nueva ética con principios nuevos o de una nueva aplicación de los principios éticos tradicionales (Spitter), hay acuerdo sobre la importancia de los problemas que plantea. También se ha llegado a hablar de ecofilosofía (Skolimowski). El enfoque ético pide un cambio de actitudes y de acciones mientras que el enfoque filosófico más general aboga por un cambio de esquemas mentales.

Aquí me concentraré en el enfoque ético de la ecología y partiré del supuesto de que la problemática que abordaré pertenece al campo de la ética aplicada y de que, por consiguiente, podemos abordar dicha problemática dentro del marco de principios éticos conocidos. No requerimos de una nueva ética, sino de la extensión de nuestra ética en cualquiera de sus variantes. En este trabajo exploraré la aplicabilidad de los principios éticos del utilitarismo a la problemática ambiental.

Simplificando un poco, puede decirse que el utilitarismo es la doctrina ética que sostiene como norma la búsqueda del mayor bienestar posible para el mayor número de individuos posible. Aunque para algunos filósofos el utilitarismo no es satisfactorio, algunos de ellos reconocen que es quizás el único que es operativo

\footnotetext{
Instituto de Investigaciones Filosóficas, UNAM.

* Texto leído en el VI Seminario Interdisciplinar sobre "Algunos aspectos de la Ecología", organizado por el Departamento Académico de Estudios Generales, TTAM, primavera de 1990 .
} 
políticamente hablando. Algunos filósofos, al extender el alcance de la ética hacia las otras especies animales, han adoptado el utilitarismo (Singer), y otros han defendido una combinación de utilitarismo y deontologismo (Hare).

El utilitarismo puede presentar varias caras, de manera que rechazar una de sus presentaciones no implica el rechazo de las otras. Así, Moore criticó el utilitarismo hedonista, que identifica la felicidad con el placer físico, pero a su vez propuso un utilitarismo ideal o eudaimonista, que identifica la felicidad con una vida buena. El panorama es, pues, complejo, y puede resumirse en el siguiente cuadro:

I. 1. Utilitarismo hedonista.

a. Cuantitativo (Bentham).

b. Cualitativo (Mill, iSidwick?).

2. Utilitarismo ideal o eudaimonista (Moore, Rashdall).

3. Utilitarismo de preferencias (Harsanyi).

II. 1. Utilitarismo positivo (Bentham, Mill).

2. Utilitarismo negativo (Epicuro, ¿Popper?, Singer).

III. 1. Utilitarismo descriptivo (Bentham).

2. Utilitarismo normativo (Mill, Sidwick).

IV. 1. Utilitarismo de actos (a corto plazo).

a. Egoista ( ¿Aristipo?, iEpicuro?).

b. Universalista (Bentham, Mill, Sidwick, Moore, Rashdall, Hare),

2. Utilitarismo de reglas (a largo palazo).

a. De reglas de hecho (Toulmin, Nowell-Smith).

b. De reglas posibles (Mill, Harrod).

Al cuadro anterior podemos añadir una división que proviene de 
la crítica que algunos eticistas ambientales han hecho a la ética tradicional en el sentido de que ésta se ha centrado hasta ahora en el hombre. Tenemos, pues, dos enfoques de la ética:

V. 1. Antropocéntrico (ética tradicional, Murdy).

2. No antropocéntrico.

a. Zoocéntrico (Singer).

b. Biocéntrico (Schweitzer).

c. Fisiocéntrico (Aldo Leopold, Berry, Arne Naess, Skolimowski, Stone, Tribe, Rolston).

Aunque algunos autores, como Murdy, piensan que necesitamos cualificar nuestro antropocentrismo haciéndolo un antropocentrismo racional en el que el hombre no sea la medida de todas las cosas pero cuyos valores sigan teniendo prioridad sobre valores no humanos (Blackstone), la mayor parte pone el énfasis en la necesidad de ampliar nuestra noción de valor, de manera que ésta rebase un antropocentrismo estrecho, pero las opiniones se dividen sobre hasta dónde debe concederse valor moral intrínseco a los existentes no humanos (Regan). La ética fisiocéntrica, que adjudica valor intrínseco moral a todo individuo natural (ríos, montes, piedras, etc.) ha sido calificada por sus adversarios de igualitarismo biótico radical (Blackstone), en tanto que sus defensores hablan de ecología profunda y sostienen que los demás enfoques constituyen un ambientalismo superficial (Naess), puesto que conceden a los no humanos sólo un valor instrumental. Mi posición al respecto se irá aclarando a lo largo de este trabajo. En este momento deseo señalar solamente que también podemos hablar de un utilitarismo antropocéntrico como opuesto a un utilitarismo no antropocéntrico con sus respectivas subdivisiones, y que en la medida en que al eticista le interesan moralmente, por las razones que sean, los ecosistemas como totalidades, se puede decir que aboga por una ética holista. Según los biólogos Stanley y Barbara Salthe hay dos escuelas de ecología: la ecología de comunidades y la ecología de sistemas. La primera se concentra en las interacciones entre poblaciones y organismos (predación, competencia, etc.) y su enfoque es particularista. La segunda, en cambio, se ocupa de la organización global de 
los flujos de materia y energía y ve a los ecosistemas como entidades individuales. Este enfoque, dicen ellos, es el más apto para la consideración moral de los ecosistemas.

Dicho lo anterior, deseo adelantar que, de los utilitarismos mencionados, la mejor opción me parece la de un utilitarismo ideal, negativo, normativo, de reglas posibles, holista, no antropocéntrico y zoocéntrico. Veamos ahora con mayor detalle las tesis del utilitarismo.

El utilitarismo se basa en el llamdo "principio de utilidad". Para Bentham, dicho principio aprueba o desaprueba cualquier acción, según la tendencia a aumentar o disminuir la felicidad de la parte cuyo interés está en juego (Bentham, cap. 1, sec. 2), y el principio de la máxima felicidad es el que dice que el único fin correcto, adecuado y universalmente deseable de la actividad humana es la máxima felicidad de todos aquéllos cuyo interés está en juego (id.).

De manera similar, para Mill "las acciones son correctas en la medida en que tienden a producir lo opuesto de la felicidad" (Mill, 10). La noción de tendencia es aquí importante, porque aunque los sacrificios no acarrean felicidad inmediata, son correctos en la medida en que tienden a promover la felicidad y eliminar la infelicidad. La infelicidad temporal es permisible en la medida en que apunta hacia una felicidad duradera. Nos dice Mill que "el fin último... es una existencia exenta de dolor en la medida de lo posible, y tan rica como sea posible en goces, tanto en cantidad como en calidad... Podría segurarse una existencia como la descrita, en la máxima medida posible, a toda la humanidad; y no solamente a ella, sino en la medida en que la naturaleza de las cosas lo permita, a la totalidad de la creación senciente" (Mill, 16) (subrayado mío). Así pues, para Mill "la única autorrenuncia aprobada por la moral utilitarista es la dedicación a la felicidad, o a algunos de los medios para la felicidad, de otros, ya sea de la humanidad colectivamente, ya sea de los individuos dentro de los límites impuestos por el interés colectivo de la humanidad" (Mill, 22). Alguien podría preguntarse por qué alguien habría de sacrificarse por la felicidad de otro individuo o de alguna colectividad. La respuesta de Mill es que "el fundamento, la base del sentimiento a favor de la moral utilitarista es la de los sentimientos sociales de la humanidad -el deseo de estar en unidad con nuestras compañeras las creaturas" (Mill, 40). Se 
podría objetar que tales sentimientos sociales constituyen un fundamento muy débil, pues no son dichos sentimientos precisamente los que nos han llevado al estado en que nos encontramos. Pero Mill piensa, al igual que otros eticistas, que la conciencia moral ha evolucionado y continúa evolucionando. Por ello afirma que "este fundamento se fortifica con la influencia de la civilización que avanza" (ibid.). Sin embargo, "aún no sentimos esa totalidad de simpatía hacia todos los demás, porque aún vivimos en un estado comparativamente temprano del avance humano" (Mill, 42).

Mill concibe la felicidad como placer y ausencia de dolor y la infelicidad, correlativamente, como dolor y privación de placer. El placer y el dolor podían, para Bentham, ser medios en términos de duración e intensidad; de esta manera quedaban, para Bentham, sentadas las bases del cálculo hedonista, el cual ha mostrado no ser viable. Mill modificó el utilitarismo de Bentham introduciendo la distinción entre placeres superiores e inferiores. Los primeros son mentales y conducen a la felicidad, mientras que los segundos son corporales y conducen al contento. Para Mill, la sanción última del principio de utilidad está dada por los sentimientos de la conciencia de la persona individual acompañados de un sentimiento de simpatía hacia los demás. De esta manera, el interés individual se supedita al interés colectivo o, mejor aún, el interés del individuo coincide con el interés colectivo. La noción de justicia juega también un papel en el utilitarismo de Mill, quien dice: "Me parece que el deseo de castigar a una persona que haya hecho daño a algún individuo es el resultado espontáneo de dos sentimientos, ...el impulso de autodefensa y el sentimiento de simpatía" (Mill, 63). Y añade: "Me parece que el sentimiento de justicia es el deseo animal de repeler o vengar una herida o daño hecho a uno mismo o a aquéllos con quienes uno simpatiza, ampliado de manera que incluya a todas las personas, en virtud de la capacidad humana de simpatia extendida y de la concepción humana de autointerés inteligente" (Mill, 65).

Ahora bien, el utilitarismo hedonista de Bentham y Mill (Más el del primero que el del segundo) es fácilmente criticable. Se la ha ridiculizado diciendo que busca el placer por el placer mismo, refiriéndose especialmente a los placeres sensuales. Pero, como ya quedó indicado, Mill distinguió entre placeres mentales y placeres 
corporales y dio prioridad a los primeros. Sin embargo, la línea divisoria de esta distinción cartesiana no es clara, pues ciertos placeres ligados a los sentidos pueden ser considerados superiores a ciertos placeres mentales, por ejemplo, el placer de degustar un vino excelente en oposición al placer de jugar serpientes y escaleras. Por otro lado, el utilitarismo de actos egoísta se centra en el placer del individuo aun sobre el placer o bienestar social. El liberalismo capitalista de nuestros días fomenta de hecho tal tipo de hedonismo. El productor busca la ganancia inmediata y el consumidor busca la satisfacción imediata de sus necesidades naturales y de sus necesidades creadas. Se trata de un utilitarismo de placer a corto plazo (y de cortas miras) que ha causado graves daños a los ecosistemas, de los cuales la humanidad forma parte, tanto en la forma de ecosistema urbano como en la forma de ecosistemas más amplios.

El cálculo hedonista propuesto por Bentham es poco menos que imposible, pues 1) supone la mensurabilidad del placer y 2) ignora que la sensación de placer es altamente subjetiva. El hedonismo cualitativo de Mill reconoce que ciertos placeres (los mentales) deben ser preferidos a otros (los corporales), pero se carece de un criterio preciso para distinguir unos placeres de los otros, si es que ello es posible.

Lo anterior está ligado a la noción de calidad de vida. ¿En qué consiste incrementar la calidad de vida? La respuesta más burda consiste en decir que se trata de incrementar el poder adquisitivo de bienes de consumo. Pero lo que se necesita es una noción holista de calidad de vida que atienda al desarrollo integral del sadividuo, a su relación con otras especies capaces de sufrir, y al equilibrio de los diversos ecosistemas que constituyen la biósfera. Esto puede lograrse con un utilitarismo normativo de reglas posibles que tome en cuenta el contexto específico de cada ecosistema.

Existe el peligro de cometer la falacia que Moore criticó en la prueba de Mill del principio de utilidad. El hecho de que algo sea deseado no es prueba de que sea deseable. Todo el mundo desea su propia felicidad. De aquí no se sigue que la felicidad de alguien sea deseable (o sea, que deba ser deseada) si ésta entra en conflicto con el interés colectivo, es decir, con las reglas de convivencia o de coexistencia (en el peor de los casos) o con la meta de la solidaridad y el espíritu de cooperación (en el mejor de los casos). Un utilita- 
rismo holista aplicado a la ecología debe elaborar una teoría de lo moralmente deseable que proporcione reglas de conducta que equilibren el interés colectivo con el interés individual, y en que la noción de calidad de vida esté supeditada a estas reglas. El interés colectivo debe ser no antropocéntrico y no debe ser especieista, para adoptar el término de Peter Singer para describir la actitud que se deriva de discriminar a otros individuos por el simple hecho de que no pertenecen a nuestra especie.

Las encuestas, por consiguiente, no definen la noción de calidad de vida al averiguar qué es lo que la gente desea. Si un alto porcentaje de los encuestados resultase ser feliz viendo muchas películas de violencia o comiendo a menudo huevos de tortuga, y resulta que ambos deseos redundan en detrimento de la estabilidad social o van en contra del bienestar de otra especie, la obtención de dichos deseos no puede ser indicativa de un alto nivel de calidad de vida. Aunque parecería que el principio de utilidad está dirigido a buscar el incremento de la felicidad de las mayorías a partir de lo que las mayorías de hecho desean, es decir, de lo que consideran como su felicidad, quienes interpretan así el principio de utilidad han prestado poca atención al capítulo 5 de Utilitarismo de Mill, donde conecta el principio de utilidad con la noción de justicia, e insisten en negar que bajo el concepto de felicidad Mill tuviese el derecho de incluir los placeres intelectuales, estéticos y morales. De hecho el utilitarismo ideal de Moore efectúa dicha inclusión. El principio de utilidad, bien entendido, busca que el máximo número posible de miembros de la sociedad maximice su felicidad o ciudaimonía (vida buena) dentro de los límites de la no obstrucción del interés colectivo, y en la medida en que éste es condición de posibilidad de la realización del interés individual.

A esta concepción del utilitarismo no se le aplican cierto tipo de objeciones como la siguiente: supóngase una sociedad de 100 ciudadanos, en que 51 son amos y 49 son esclavos. Aquí la felicidad de la mayoría sería la felicidad de los amos. El utilitarista burdo aprobaría dicha sociedad, y la aprobaría más si los amos hubiesen lavado el cerebro a los esclavos de manera tal que éstos fuesen felices siendo esclavos. Piénsese en la misma sociedad, y en que 51 ciudadanos son felices tirando la basura en la calle y 49 son infelices por ello. Es obvio que se necesita de un utilitarismo refinado que 
se combine con algún tipo de ética deontológica que establezca algún tipo de norma que complemente al principio de utilidad. Es por ello que autores como Hare proponen una ética utilitarista kantiana, tratando así de combinar lo mejor de las teorías deontológicas con lo mejor de las teorías teleológicas o consecuencialistas. Frankena propone lo que llama una "teoría deontológica mixta" que tome como principios básicos de la moralidad el principio de justicia y el principio de utilidad, que para Frankena se deriva del que él llama "el principio de benevolencia", a saber, haz el bien y evita el mal.

Según Frankena y otros autores, el hecho de que Mill haya incorporado la noción de justicia como parte del utilitarismo en el capítulo 5 de su libro, es inconsistente con là posición que sostuvo en el resto de la obra. Yo no estoy tan seguro de ello. Lo cierto es que la formulacion del principio de utilidad ha llevado a que florezca el utilitarismo de acto como la interpretación correcta del principio. El utilitarismo de actos, sin embargo, ha sido objeto de varios ataques. Uno de ellos consiste en los argumentos a veces llamados de "promesas en una isla desierta". Supongamos, por ejemplo, que el publicista y filántropo Eulalio Ferrer o el cantante y filántropo Plácido Domingo, y yo (o usted) nos encontramos solos en una isla, y que nuestro amigo filántropo está muriendo, por lo cual nos entrega una enorme suma de dinero haciéndonos prometer antes que, si sobrevivimos, se la entregaremos a cierta persona cuyos datos nos da. Cuando liegamos a México averiguamos sobre dicha persona (que resulta ser un hijo ilegítimo no reconocido de nuestro difunto amigo), y nos enteramos de que es una persona que posee una fortuna nada modesta y que además es terriblemente egoista, por lo cual decidimos no entregarle el dinero, sino más bien entregarlo, en el caso de Eulalio Ferrer, al MEM (Movimiento Ecologista Mexicano), sabiendo además que él simpatizaba con la causa ecologista, o, en el caso de Plácido Domingo, entregamos el dinero a la CONAMUP (Comité Nacional de Movimientos Urbanos Populares) para la edificación de viviendas dignas rodeadas de áreas verdes, conocedores de la preocupación de Plácido Domingo por los damnificados del temblor de 1985 en la Ciudad de México. La ruptura de mi promesa contribuirá más al bien común que su cumplimiento. Como nadie conoce mi promesa, incluyendo al be- 
neficiario, nadie me retirará su confianza ni nadie se sentirá frustado. Puedo inclusive decir que el finado me pidió que entregase el dinero a la institución en cuestión. El utilitarista de actos no podría desaprobar mi conducta. Sin embargo, dicha conducta se opone a la opinión moral común de que debemos siempre mantener nuestras promesas. El utilitarista de reglas dirá, en cambio, que debemos actuar conforme al deber prima facie de mantener siempre nuestras promesas, pues a la larga ello redundará en un mayor bien para la humanidad al no hacernos perder la confianza en la institución de la promesa, de lo cual se beneficiarían también el MEM y la CONAMUP.

Hay que aclarar que a menudo se habla del utilitarismo de reglas como una posición en la que a todos los casos se les debe dar siempre la misma solución. Podríamos llamar a éste un utilitarismo de reglas rígido, en contraposición a un utilitarismo de reglas moderado según el cual habrá ciertas excepciones incorporadas a la regla general. Se admitirá, por ejemplo, que no hay obligación moral de cumplir promesas hechas bajo coacción. Toda teoría moral aplicada debe dar respuesta a casos difíciles y conflictivos, ya no como el que acabo de formular, sino más concretos y palpables. Se ha argumentado, por ejemplo, que la industria nuclear es más limpia que la industria petrolera o que la del carbón. A corto plazo, contribuiría a disminuir los malestares causados por contaminación del aire, pero el riesgo y la gravedad de las consecuencias de un posible accidente parecen pesar mucho, sobre todo si incluimos el bienestar de generaciones futuras. Tomar decisiones sobre este tipo de cuestiones requiere del apoyo de una buena teoría de decisiones que disponga de métodos adecuados de evaluación de riesgos, costos y beneficios. Quizá la cantidad de felicidad o placer no pueda ser medida, pero sí se puede tener un método de evaluación de riesgos y de toma de deciones.

Dice Frankena que las teorías éticas egoístas piensan demasiado en la felicidad personal e ignoran la noción de deber, y que las teorías deontológicas enfatizan mucho el deber e ignoran el bienestar social, y que el utilitarismo trata de subsanar estas deficiencias, pero que en realidad no puede si no se le añade algún componente deontológico. Parecería que ni el deontologismo puro ni el utilitarismo puro pueden fundamentar la conducta moral, y que es nece- 
sario echar mano de una combinación de ambos, llámesele deontologismo utilitarista o utilitarismo deontológico.

Dar contenido concreto y universal a la noción de felicidad es no sólo imposible, sino ilegítimo. El utilitarismo no debe tratar de imponer un modelo concreto de felicidad. Debe tener un conjunto de reglas mínimas, es decir, establecer la satisfacción de necesidades básicas como condición de posibilidad de la realización, por parte de los individuos, de diversas concepciones de la felicidad dentro de los límites de la convivencia o coexistencia. Una tarea más clara, para una concepción utilitarista de la moral, consiste en la minimización de las causas de dolor y la infelicidad, tales como la injusticia económica, la represión de las libertades de expresión y movimiento, y las enfermedades físicas y mentales.

Un ecologismo utilitarista holista buscará en primer término reducir a su mínimo las causas de malestar de las poblaciones humanas y no humanas relacionadas con problemas ambientales o ecosistémicos, creando conciencia, por ejemplo, sobre el beneficio social mediato que se obtendrá con una serie de sacrificios individuales inmediatos (realizados tanto por el administrador como por el productor y el consumidor). En una segunda etapa buscará el mantenimiento de las condiciones de posibilidad de desarrollo equilibrado de las diversas poblaciones para luego buscar, finalmente, la implantación de condiciones óptimas dentro de los diversos ecosistemas. 